\title{
CORRIGENDA
}

\section{Variability of urinary concentrations of polycyclic aromatic hydrocarbon metabolite in general population and comparison of spot, first-morning, and 24-h void sampling}

Zheng Li, Lovisa C. Romanoff, Michael D. Lewin, Erin N. Porter, Debra A. Trinidad, Larry L. Needham, Donald G. Patterson Jr and Andreas Sjödin

Journal of Exposure Science and Environmental Epidemiology (2013) 23, 109-110; doi:10.1038/jes.2012.93

Correction to: Journal of Exposure Science and Environmental Epidemiology (2010) 20, 526-535; doi:10.1038/jes.2009.41

Tables 2 and 3 contained transcription errors that gave rise to minor errors in the calculated sample-size results. The corrected tables are reproduced below in their entirety and the values presented correctly. The author regrets the error.

Additional corrections are described below.

Abstract: The tenth sentence in the abstract should have read: "Intraclass correlation coefficients of 1-PYR levels were 0.55 for spot urine samples, 0.65 [not 0.60] for first-morning voids, and 0.77 [not 0.76 ] for 24-h voids, indicating a high degree of correlation between urine measurements collected from the same subject over time".
Statistical Analysis: In the third paragraph, eighth sentence (beginning "The percentage differences"), "controls vs cases" should have been "controls vs exposed group".

In the last sentence of that section, "(one-tailed)" was omitted from the definition of the next to last term; it should have read " $Z_{y}=y$ th percentile of a standard Gaussian distribution (one-tailed)".

Sample Size Recommendation: The fifth sentence in the first paragraph should have read: "The ICCs for 1-PYR in our study were $0.55,0.65$ [not 0.60], and 0.77 [not 0.76], for spot samples, firstmorning-voids, and 24-h voids, respectively, indicating considerable agreement between repeated measurements". The third sentence in the second paragraph should have read "For example, taking an additional sample per person reduces the sample size by $23 \%, 17 \%$ [not $20 \%$ ], and $12 \%$ [not $13 \%$ ] for spot samples, firstmorning, and 24-h voids, respectively".

Table 2. Variance apportionment for creatinine-adjusted concentrations of $4 \mathrm{PAH}$ metabolites in urine samples from eight subjects over a period of 7 days.

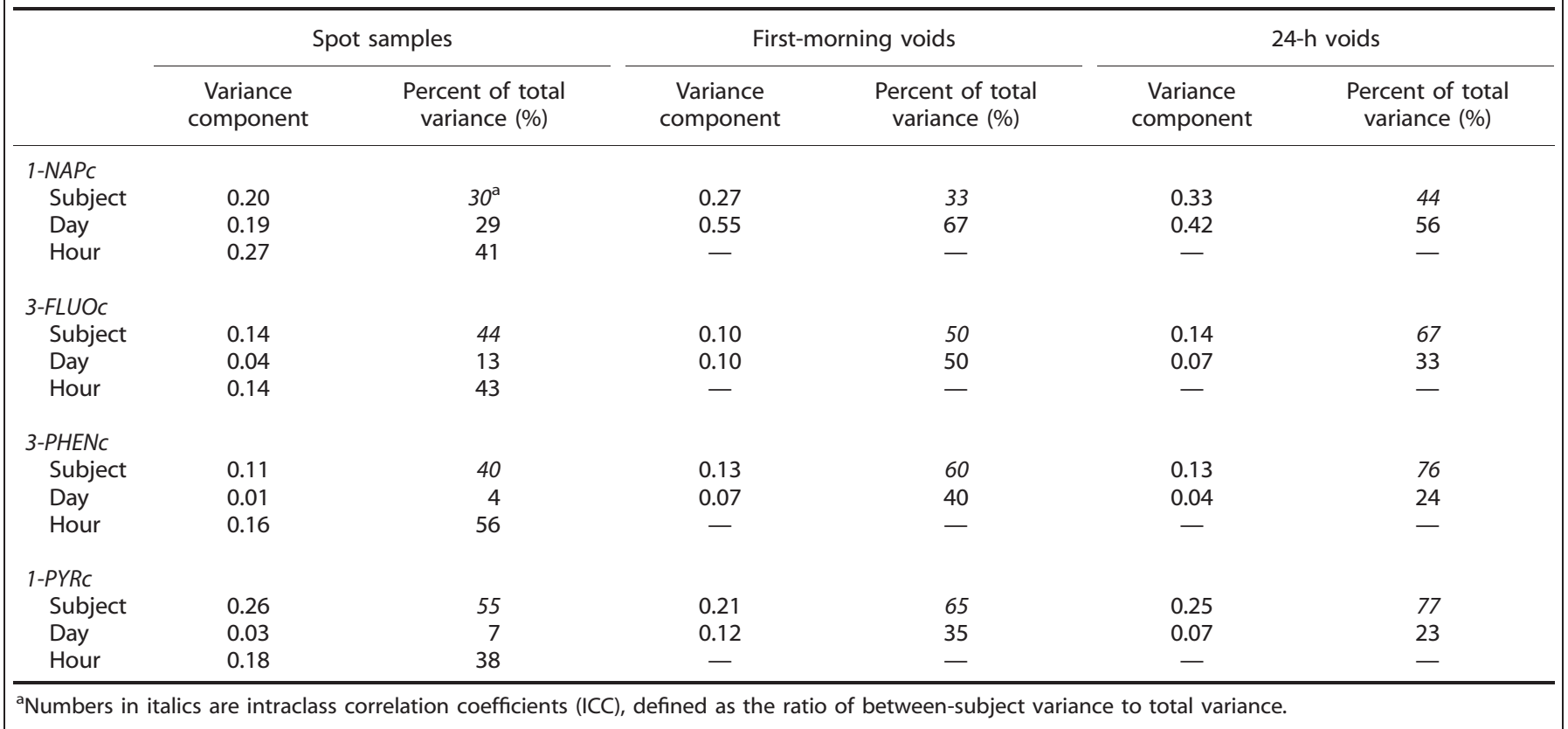


Table 3. Estimated number of samples needed to detect a difference of $10 \%, 25 \%, 50 \%$, and $100 \%$ in the 1-hydroxypyrene geometric mean concentration with a statistical power of $80 \%(P<0.05)$, for single and repeated sampling for spot, first-morning, and 24 -hour void sampling.

\begin{tabular}{|c|c|c|c|c|c|c|c|c|c|c|c|c|}
\hline \multirow[t]{3}{*}{ Target \% difference on GM } & \multicolumn{12}{|c|}{ Number of repeated samples } \\
\hline & \multicolumn{4}{|c|}{ Spot samples } & \multicolumn{4}{|c|}{ First-morning voids } & \multicolumn{3}{|c|}{ 24-h voids } & \multirow[b]{2}{*}{4} \\
\hline & 1 & 2 & 3 & 4 & 1 & 2 & 3 & 4 & 1 & 2 & 3 & \\
\hline \multicolumn{13}{|c|}{ Wet weight concentration (ng/l urine) } \\
\hline $10 \%$ & 1069 & 624 & 475 & 401 & 618 & 420 & 353 & 320 & 296 & 230 & 208 & 197 \\
\hline $25 \%$ & 195 & 114 & 87 & 73 & 113 & 77 & 64 & 58 & 54 & 42 & 38 & 36 \\
\hline $50 \%$ & 59 & 34 & 26 & 22 & 34 & 23 & 20 & 18 & 16 & 13 & 11 & 11 \\
\hline $100 \%$ & 20 & 12 & 9 & 8 & 12 & 8 & 7 & 6 & 6 & 4 & 4 & 4 \\
\hline \multicolumn{13}{|c|}{ Creatinine-adjusted concentration ( $\mathrm{ng} / \mathrm{g}$ creatinine) } \\
\hline $10 \%$ & 606 & 470 & 424 & 401 & 415 & 343 & 318 & 306 & 399 & 353 & 338 & 330 \\
\hline $25 \%$ & 111 & 86 & 77 & 73 & 76 & 63 & 58 & 56 & 73 & 64 & 62 & 60 \\
\hline $50 \%$ & 33 & 26 & 23 & 22 & 23 & 19 & 18 & 17 & 22 & 19 & 19 & 18 \\
\hline $100 \%$ & 11 & 9 & 8 & 8 & 8 & 6 & 6 & 6 & 8 & 7 & 6 & 6 \\
\hline
\end{tabular}

\section{Estimating exposures to indoor contaminants using residential dust}

Todd Whitehead, Catherine Metayer, Patricia Buffler and Stephen M. Rappaport

Journal of Exposure Science and Environmental Epidemiology (2013) 23, 110; doi:10.1038/jes.2012.95

Correction to: Journal of Exposure Science and Environmental Epidemiology (2011) 21, 549-564; doi:10.1038/jes.2011.11

The unit of measure given for median dust concentrations for BDE-47, BDE-99 and BDE-209 on page 551 was incorrect. The concentrations should have been given as $\mu \mathrm{g} / \mathrm{g}$ instead of $\mathrm{mg} / \mathrm{g}$. The authors regret the error. 